\title{
DO MUNDANO AO SAGRADO: O PAPEL DA EFERVESCÊNCIA NA TEORIA MORAL DURKHEIMIANA
}

\author{
Raquel Andrade Weiss \\ Universidade Federal do Rio Grande do Sul - Brasil
}

Resumo: Meu objetivo neste artigo é discutir o significado do conceito de efervescência na obra durkheimiana e apontar o papel que esse processo desempenha em relação à sua teoria moral. De modo geral, a argumentação versa em torno da articulação de três pressupostos estruturais da teoria moral durkheimiana, quais sejam, 1) a vinculação entre sagrado e ideal moral, 2) a concepção acerca da natureza humana como sendo essencialmente dual e 3) a proposta normativa de Durkheim de institucionalização de uma moralidade laica. Ao final, proponho ao leitor uma reflexão sobre a pertinência de sua defesa de um "sagrado laico" a partir dos desafios morais que caracterizam o mundo contemporâneo.

Palavras-chave: Durkheim, efervescência, moral, sagrado.

\begin{abstract}
My main purpose in this paper is to argue on the meaning of the concept of effervescence within durkheimian work, pointing to the role played by this process in the general scenario of his moral theory. Roughly speaking, the argumentation is grounded on the articulation between three structural premises of Durkheimian moral theory, namely: 1) the attachment between the sacred and the moral ideal; 2) his conception about human nature as essential dual and 3) Durkheim 's normative defence of institutionalization of secular morality. Towards the end I incite the reader to think about the pertinence of his defence of a "secular sacred", in the light of the moral challenges in contemporary world.
\end{abstract}

Keywords: Durkheim, effervescence, moral, sacred. 


\section{Introducão}

O ponto de partida deste artigo, a ser discutido no decorrer de toda a argumentação, é a afirmação de que o conceito de sagrado - um dos mais fundamentais do arcabouço teórico durkhemiano - constitui uma peça central para a compreensão e, mais do que isso, para a fundamentação da teoria moral durkheimiana, e que tem no processo de efervescência sua instância criadora. A premissa que sustenta essa afirmação geral é a de que o elemento mais nuclear do fenômeno moral é aquilo definido por Durkheim como sendo "o bem", que é aquilo que faz com que a moral seja não apenas uma regra coercitiva mas, sobretudo, um ideal que se deseja realizar (cf. Durkheim, 1887, 1890, 1901, 1909, 1911, 2008; Weiss, 2011, 2012a).

Uma vez aceita tal premissa, procurar-se-á mostrar que a centralidade do conceito de sagrado se deve a uma dupla razão. Primeiramente, ao argumentar em favor de uma origem comum do sagrado e do ideal, espera-se elucidar como a apreensão do processo social que engendra o sagrado explica, ao mesmo tempo, a gênese dos ideais morais. Em segundo lugar, toma-se a noção de sagrado como o cerne da justificativa das proposições normativas de Durkheim, estruturadas sobre a convicção quanto à possibilidade e à necessidade de se construir um novo sagrado para a sociedade moderna. Trata-se de sua defesa do "individualismo moral", que consistiria em um sistema de crenças que colocaria a pessoa humana como o sagrado irredutível das consciências contemporâneas.

A partir desse quadro geral apresentado nas diversas etapas da presente discussão será ainda possível apreender a concepção do autor a respeito da natureza humana como sendo essencialmente dual, e sua posição em relação ao lugar da religião no mundo moderno. Em relação a isso, pode-se afirmar que essa posição pode ser entendida como uma defesa bastante peculiar de um certo tipo de secularismo, o que ajuda a introduzir novas perspectivas neste que é um dos debates mais acalorados da teoria social contemporânea, que mobiliza autores dos mais diversos campos do conhecimento, como a antropologia, a sociologia, a filosofia, o direito e mesmo a teologia. Sem pretender adentrar muito profundamente nessa questão, o presente artigo oferece alguns elementos de sua posição em relação a esse tema, bastante incisiva e controversa, e que pode ser resumida em sua defesa de um "sagrado laico", por mais contraditória que essa posição possa parecer.

Horizontes Antropológicos, Porto Alegre, ano 19, n. 40, p. 395-421, jul./dez. 2013 


\section{Os ideais sociais como representações sagradas}

Uma primeira coisa a se ter em consideração quando vamos analisar a teoria moral durkheimiana é que, para o autor, a moral é um fenômeno que tem uma origem social. Portanto, inclusive os "ideais", que são o coração de todo princípio moral, são produções coletivas. Ora, para o autor, toda reunião de grupo, assembleias, etc. é um momento dinamogênico, que contribui para reavivar a percepção dessa realidade sui generis. Mas há momentos em que essa força atinge uma intensidade excepcional (Durkheim, 1890), justamente porque a interação entre as consciências é mais frequente e mais ativa: como tive ocasião de discutir em outros contextos (Weiss, 2011, cap. 4), os períodos históricos de transição são um desses momentos mais característicos, em que existe um abalo no mundo tal como ele é. Por isso, inclusive, que os momentos de crise são particularmente férteis. É essa grande concentração energética que permite criar o novo, conforme podemos ver no seguinte trecho de Les formes élémentaires de la vieu religieuse, doravante Les formes élémentaires:

Além desses estados passageiros ou intermitentes, há outros mais duráveis, nos quais essa influência fortalecedora da sociedade se faz sentir com maior continuidade e, com frequência, com maior intensidade. Há certos períodos históricos nos quais, sob a influência de algum grande abalo coletivo, as interações sociais se tornam mais frequentes e mais ativas. Os indivíduos se reúnem mais. Resulta disso uma efervescência geral, característica das épocas revolucionárias ou criadoras. Ora, essa superatividade tem por efeito uma estimulação geral das forças individuais. Se vive mais e de forma diferente do que nos tempos normais. As transformações não são apenas de nuanças, de graus; o homem realmente se torna outro. As paixões que o agitam são de tal intensidade que ele não pode satisfazê-las senão mediante atos violentos, desmesurados: atos de heroísmo sobre-humano ou de barbárie sanguinária. Sob a influência da exaltação geral, vemos o mais medíocre ou mais inofensivo burguês seja em herói, seja em carrasco. (Durkheim, 1968, p. 300-301, tradução minha).

Assim, a formação do ideal depende de determinadas condições empíricas que podem ser observadas, porque é um produto da vida social. Mais do que isso, é um produto natural dessa vida, na medida em que não depende apenas de procedimentos deliberados, conscientes, mas também é fruto do fato básico da interação em condições particulares, que garantem a produção 
da efervescência. É isso o que permite que a sociedade perceba a si mesma, e é essa autopercepção que se expressa no sentimento de sagrado que passa a ser um atributo de pessoas, coisas e ideias.

As concepções ideais são uma tradução desse fenômeno de exaltação da vida moral, leia-se, da vida coletiva, naquilo que ela tem de mais essencial: o agir e pensar em comum, no qual as barreiras que constituem as individualidades são mais tênues, garantindo uma verdadeira comunhão das consciências. Assim, um fato que é basicamente "mecânico" se transforma em um acontecimento psíquico ou, por que não, espiritual. Mas note-se que não basta que as pessoas estejam fisicamente reunidas em um mesmo espaço; se assim o fosse, tomar o metrô em horário de pico já resultaria num processo de efervescência. É preciso uma ação comum e um pensamento compartilhado, o que caracteriza os acontecimentos rituais. Essa é a condição para que as consciências estejam mais suscetíveis à ação recíproca e desencadeiem esse processo de superexcitação que engendra a dinamogenia.

Esse processo de efervescência não é pensado apenas como um elemento necessário para a criação do ideal, mas é fundamental para sustentar a própria sociedade real, na medida em que oferece o suprimento de energia necessário para que os indivíduos deem continuidade à sua existência como seres sociais, que agem moralmente no seu cotidiano, que interagem e que fazem de sua vida algo além da simples persecução de seus interesses inteiramente pessoais. Porque o sentimento de sagrado e, portanto, a vida moral não podem existir apenas nesses momentos excepcionais, eles precisam existir de forma contínua para que a sociedade enquanto tal, enquanto expressão de sua vida ideal, mas que é absolutamente real, possa se manter.

A discussão sobre o sagrado, que aqui se dá sob a forma de uma discussão sobre os ideais, explica também os conflitos e dilemas éticos que podem ser travados no seio da sociedade, e que não devem ser vistos como uma tensão entre o real e o ideal, mas como um confronto entre ideais e, por que não, como um confronto entre sagrados, o que ajuda muito a elucidar a natureza dos embates éticos contemporâneos, que nos colocam diante de pontos de vista que parecem irredutíveis, justamente porque temos em nossas sociedades altamente plurais diferentes sagrados que conflitam entre si, sem que se tenha um ponto de vista mais abrangente que permita solucionar a questão de forma consensual, isto é, sem ofender um ou outro dos muitos sagrados particulares. 
Mas Durkheim não parecia particularmente preocupado com essa questão, que considerava um fato normal da vida coletiva, talvez justamente porque tivesse bastante fé no futuro do ideal do individualismo como um sagrado suficientemente abrangente, que poderia operar como fiel da balança quando estivessem em jogo questões realmente fundamentais. Ou talvez porque o único conflito que percebesse era aquele entre o "ideal de ontem" e o "ideal de hoje", como se o "ideal de hoje" fosse algo facilmente apreensível e unânime, como se o ideal de hoje pudesse ser sempre um só. Mas essa é apenas uma hipótese, que não pode senão permanecer como tal. Vamos olhar, então, para os argumentos que temos, para ver o que é possível apreender daquilo que foi dito, em vez de prolongar as especulações sobre o não dito:

Assim, quando se opõe a sociedade ideal à sociedade real como se fossem dois antagonistas que nos colocam em sentidos contrários, o que se percebe e o que se opõe são abstrações. A sociedade ideal não está fora da sociedade real; ela a constitui. Longe de estarmos diante de dois polos que se repulsam, a verdade é que não podemos nos vincular a uma sem nos vincularmos à outra. Porque uma sociedade não é apenas constituída pela massa dos indivíduos que a compõem, pelo solo que ela ocupa, pelas coisas de que se serve, pelos movimentos que realiza, mas, acima de tudo, pela ideia que ela faz de si mesma. E, sem dúvida, chega sempre um momento no qual ela hesita em relação à maneira com que deve se conceber: ela se sente dilacerada em sentidos divergentes. Mas esses conflitos não são entre o ideal e a realidade, mas entre ideais diferentes, entre aquele de ontem e aquele de hoje, entre aquele que possui a autoridade da tradição e aquele que está em vias de surgir. (Durkheim, 1968, p. 604, tradução minha).

É fácil então perceber que, ao defender o ideal do individualismo, Durkheim não acreditava estar negando a sociedade real, mas afirmando um ideal ainda não plenamente realizado, que ainda não gozava da autoridade da tradição, mas que havia sido produzido pela coletividade do mesmo modo que o ideal anterior. Portanto, se não gozava ainda dessa autoridade, podia ao menos gozar do respeito de que todo ideal criado coletivamente é objeto, em virtude do mero fato de ter sido criado coletivamente. E isso ocorre porque o sagrado se superpõe a essa representação coletiva, que se torna um ideal exatamente em virtude desse processo mediante o qual ela surgiu.

A afirmação mais fundamental, portanto, é a de que é a sociedade o verdadeiro objeto de respeito, mesmo que o novo ideal que a representa ainda 
não tenha sido fixado pela tradição. Entramos agora em uma questão bastante importante, qual seja, a ideia de autoridade moral e de respeito, que são indispensáveis para se tentar pensar como Durkheim fundamenta a moral em geral e o novo ideal moral defendido por ele. A seguir vemos como ele caracteriza essa ideia de respeito a partir da afirmação de que a sociedade é uma força moral e não apenas uma força física:

Todavia, se a sociedade obtivesse de nós concessões e sacrifícios a partir de uma coerção material, ela não poderia despertar em nós senão a ideia de uma força física diante da qual cederíamos por necessidade, e não de uma potência moral tal como aquelas que as religiões adoram. Na realidade, o império que ela exerce sobre as consciências se deve menos à sua supremacia física do que à autoridade moral de que ela é investida. Se deferimos as suas ordens não é simplesmente porque ela está armada de modo a triunfar sobre nossas resistência; é, antes de tudo, porque ela é objeto de um verdadeiro respeito. (Durkheim, 1968, p. 296, tradução minha).

Podemos desde já notar o quanto essa ideia de respeito está intrinsecamente vinculada à noção de sagrado, a tal ponto que chega a ser difícil dissociá-las, porque aquilo que é digno de respeito é tudo aquilo que possui um estatuto sagrado, do mesmo modo que aquilo que é sagrado inspira alguma forma de respeito, mesmo quando se trata de um sagrado nefasto, na medida em que se refere a certa ordem de coisas que não se pode tocar impunemente. No entanto, a noção de autoridade moral parece ser anterior, pois é dessa autoridade que brota o caráter sagrado das coisas e o sentimento de sagrado que elas inspiram, que, na verdade, é uma emanação dessa autoridade mesma.

Mas qual é o significado dessa noção de autoridade moral, isto é, como é que a sociedade pode ver na coletividade esse tipo de autoridade? Em que ela consiste? Vimos que a as ações rituais engendram uma situação de efervescência, na qual as consciências agem intensamente umas sobre as outras, e isso produz um elevado excedente de energia que provoca alterações qualitativas na própria vida psíquica dos indivíduos: é nisso que consiste a dinamogenia, provocada pela interação, e que se faz sentir em cada um dos membros da coletividade.

Esse processo é o que incrementa o tônus vital, garantindo uma perpétua sustentação do ser moral. No momento em que isso acontece, percebemos que esse aporte energético que nos sustenta provém de alguma causa externa, 
que não sabemos o que é, e que representamos como uma potência moral imanente, que está em nós, mas não coincide conosco, é algo diferente, a que damos o nome de consciência moral. Portanto, a própria consciência moral não é uma ilusão ou uma construção arbitrária. Desse ponto de vista, Kant teria acertado em sua explicação sobre o mecanismo pelo qual a lei moral se manifesta à nossa vontade, como "consciência do dever", que aparece como um imperativo categórico. Mas, para Durkheim, essa consciência do dever não é exatamente o reconhecimento das leis da razão prática, ao menos não no sentido kantiano. Ela é a expressão imperativa da vida coletiva que existe em nós sob a forma de representações investidas de uma "energia" particular.

A percepção da consciência é a maneira como se representa a presença dessa força, dessa energia produzida pelo processo de dinamogenia. Portanto, os imperativos que constituem as regras morais são representações coletivas que de um lado expressam o ideal e, de outro, regulamentam a ação. Por isso, tanto as regras quanto o ideal aparecem como sagrados, como invioláveis, na medida em que essas representações aparecem como sendo investidas da força oriunda dos processos que as constituíram. Assim podemos retornar à noção de respeito e entender em que sentido ele é uma reação emotiva que experimentamos em virtude da força psíquica engendrada pela vida em grupo que, em última análise, é o que funda a ideia de autoridade moral:

Dizemos de um sujeito, individual ou coletivo, que ele inspira respeito, quando a representação que o exprime nas consciências é dotada de tal força que, automaticamente, suscita ou inibe as ações, abstraindo-se de todas as considerações feitas a respeito de seus efeitos úteis ou nocivos. Quando obedecemos a uma pessoa em virtude da autoridade moral que reconhecemos nela, nós seguimos seus conselhos, não porque eles parecem sábios, mas porque na ideia que fazemos dessa pessoa existe uma energia psíquica que é de certo modo imanente, que dobra nossa vontade e a inclina no sentido indicado. O respeito é a emoção que experimentamos quando sentimos essa pressão interior e inteiramente espiritual se produzir em nós. Então, aquilo que nos determina não são as vantagens ou os inconvenientes da atitude que nos é prescrita ou recomendada; é a maneira com que nós mesmos representamos aquilo que nos recomenda ou nos prescreve a ação. (Durkheim, 1968, p. 296, grifo meu, tradução minha).

Ora, esse respeito particular por essas "forças" é o que faz com que sejam consideradas sagradas. O sagrado é, ao mesmo tempo, o sentimento que 
elas despertam em nós, é a percepção de seu caráter excepcional que legisla e nutre e é o modo como as caracterizamos. É porque elas despertam em nós esse sentimento, que podemos chamar de respeito, que atribuímos a elas um lugar à parte no mundo, é por isso que consideramos essas forças como algo sagrado. São forças reais, mas que são elevadas à categoria de sagrado em virtude do nosso modo de percebê-las, porque estão em nós, mas não coincidem com nossa existência singular, são forças que se manifestam em nós aumentando nosso tônus vital, mas que vêm de outro lugar que não de nós mesmos. Voltando novamente a Kant, podemos dizer que se ele atribuiu o caráter imperativo com que nós representamos a lei moral à nossa dupla natureza, numênica e fenomênica - se assim não fosse a lei moral não teria a forma de um dever-, Durkheim explica o sentimento de respeito pela lei, que dobra as vontades ao mesmo tempo em que as atrai, também a partir de uma dualidade de nossa natureza, não entre existência numênica e fenomênica, mas entre ser individual e ser social.

A moral aparece ao indivíduo como dever porque existe nele uma representação interna da regra, mas que não é uma criação sua, trata-se de uma representação que lhe vem de fora. Ao mesmo tempo, a realização dessa regra lhe aparece como algo excepcionalmente bom, que provoca sentimentos que ele só experimenta quando cumpre esse dever, porque assim alimenta sua natureza social, na medida em que a força dinamogênica da coletividade lhe retribui com esse afluxo energético. O que funda, portanto, a noção de autoridade moral, e de respeito, é a ideia que fazemos dessa pessoa, individual ou coletiva, que contém em si mesma uma "energia psíquica", e é essa energia, essa força que se impõe às nossas vontades e nos faz agir do modo que essa autoridade ordena, sem que tenhamos de fazer qualquer cálculo sobre sua utilidade, sem questionar sua validade.

O que se chama de "respeito" nada mais é do que uma "emoção" que se experimenta no momento em que essa pressão é exercida, e é essa emoção que se torna o motor da ação, aquilo que ordena categoricamente que se aja tal como nos foi solicitado por essa autoridade. É uma pressão interior e espiritual: não é medo, não é coação física. É, portanto, seu ascendente moral, que é o que caracteriza a intensidade com que uma autoridade se impõe, o que garante sua eficácia. Esse ascendente, Durkheim (1968, p. 268, tradução minha) o define como "a intensidade do estado mental daquele a quem se impõe 
o mandamento". Mas por que a sociedade possui esse ascendente em relação aos indivíduos?

Primeiramente e acima de tudo, porque as maneiras de pensar e agir que ela prescreve são elaboradas em comum. É exatamente aqui que reside todo o segredo dessa "força" muito particular que constitui o respeito e que garante sua autoridade. A vivacidade de cada espírito particular ecoa nos demais, produzindo uma força mais intensa, que se faz presente nas representações coletivas. Isso aponta para a importância da opinião pública como instância originária dessa força psíquica intensa e singular que caracteriza toda autoridade moral. Uma autoridade que não encontra respaldo na opinião pública nunca se impõe como uma autoridade verdadeiramente moral. Como veremos, essa opinião é que constitui, inconscientemente, aquilo que se considera sagrado:

A opinião, coisa eminentemente social, é, portanto, uma fonte de autoridade e podemos até mesmo nos perguntar se toda autoridade não é filha da opinião. Objetar-se-á que a ciência é frequentemente a antagonista da opinião, a qual ela combate e retifica os erros. Mas ela não seria bem sucedida nessa tarefa se não gozasse de suficiente autoridade, e ela não poderia retirar essa autoridade senão da própria opinião coletiva. Se um povo não tiver fé na ciência, nenhuma demonstração científica terá influência sobre seus espíritos. Mesmo nos dias de hoje, se acontecer de haver uma resistência muito forte da opinião pública em relação à ciência, ela poderá perder sua credibilidade. (Durkheim, 1968, p. 298, tradução minha).

Se até aqui discutimos o que acontece na vida coletiva que faz com que o sagrado possa surgir, na medida em que produz situações de efervescência, ainda não está suficientemente claro como sua virtude dinamogênica se faz sentir nos indivíduos. Algumas páginas acima, afirmei que o indivíduo sente dentro de si essa força, mas que ao mesmo tempo percebe que não é uma força que brota dele, de modo que as próprias regras que ele representa lhe parecem vir de uma "consciência moral", que está nele, mas que não foi criada totalmente por ele. Como isso é possível? A resposta a tal questão deve ser buscada na concepção de Durkheim a respeito da natureza humana, que consiste em mais um elemento crucial de sua teoria que nos ajuda a desvendar de que modo ele fundamenta socialmente a moral. 


\section{Dualismo da natureza humana e individualismo: o mundano sagrado}

A importância da consideração do sagrado como via para legitimar a sociedade como criadora e destinatária da moral depende de que seja tematizado por quais razões ela é em si mesma algo necessário e desejável, para que esse ideal moral que dela brota, e que orienta as condutas sob a forma de regras, possa ser dito algo realmente bom. No entanto, não podemos afirmar existir um argumento definitivo. Aliás, a falta de sistematicidade constitui um verdadeiro obstáculo para se encontrar essas respostas mais definidas, de modo que a construção de uma explicação coerente e consistente demanda um trabalho quase detetivesco de coleta de pistas e evidências, reunidas e organizadas a partir da consideração dos princípios teóricos mais gerais que estruturam o pensamento durkheimiano. Só assim é possível alcançar uma explicação logicamente fundamentada.

Embora esse trabalho fragmentário possa ter algo de frustrante, ele é ao mesmo tempo intrigante e inspirador, na medida em que quanto mais elementos são recolhidos, mais esse retrato panorâmico vai adquirindo complexidade e sentido, abrindo novas vias que antes pareciam inexistentes, ou simplesmente levando a descobrir aporias que permaneceram sem uma solução satisfatória. Além disso, esse procedimento nos permite olhar para um pensamento que não se apresenta sempre acabado, como é esperado em um sistema, mas para um pensamento em constante busca de elucidar-se diante de si mesmo e diante do público com quem dialoga, a partir de reelaboração de conceitos, explicitação de ideias latentes ou apenas enfatizando qual dentre as muitas leituras possíveis deveria ser a mais correta a respeito de um argumento anterior. Isso aconteceu com todos os grandes livros de Durkheim, a cuja publicação se seguiram debates, artigos, cartas. Com Les formes élémentaires não foi diferente.

Um dos textos mais importantes desse esforço de elucidação do sentido principal de seu livro, no qual podemos encontrar importantes elementos para esclarecer sobre a desejabilidade da moral enquanto criação social, é Le dualisme de la nature humain et ses conditions sociales (Durkheim, 1914), no qual é analisado em detalhe um argumento que já figurara em diversas ocasiões anteriores, como em L'éducation morale (Durkheim, 2008), ou ainda no pronunciamento aos alunos na École Normale d'Auteuil (Durkheim, 
2007). Resumidamente, o principal argumento é o de que o próprio indivíduo, tal como ele existe, só é possível na medida em que é também um ser social. Sem aquilo que foi forjado pela sociedade, ele seria um animal como qualquer outro. A nossa vida intelectual, o gosto estético, o bem-estar material, todos esses são legados da civilização. Mas há algo mais do que isso. Esses bens não são um "valor opcional" que podemos escolher ter ou não ter em nossa vida, eles são partes constitutivas de nossa própria natureza, pois a natureza humana é formada por um inextrincável dualismo: ela é a um só tempo individual e social.

Como podemos perceber, esse argumento pode ser lido como a versão durkheimiana de uma questão tão antiga quanto a própria filosofia, que busca compreender a natureza do homem a partir do estabelecimento de princípios constitutivos irredutíveis e antagônicos (Paoletti, 2012). E talvez seja por essa razão mesma que o título é "o dualismo" da natureza humana e não apenas "a dualidade", como no texto publicado no ano anterior (Durkheim, 2012a, $2012 b$ ), pois, em francês como em português, esse primeiro vocábulo expressa mais claramente uma posição ética ou ontológica, caracterizando as duas partes da dualidade como opostos (Weiss, 2012a).

Aliás, o dualismo também designa a "antropologia" - em sentido filosófico - que está na base de boa parte das religiões: não se trata de uma simples dualidade, isto é, de que o ser é constituído dois princípios ou substâncias diferentes, mas por dois princípios e substâncias diferentes, irredutiveis e opostos, como o corpo e o espírito, o bem e o mal. Em Durkheim, esse dualismo assume a forma da oposição entre "ser individual" e "ser social", e entendê-lo é condição sine qua non para desvendar tudo aquilo que está por trás do conceito de sagrado como atributo real e legitimador dos ideais e preceitos morais.

\section{0 ser social e o ser individual como epítome do sagrado e profano}

Em diversos momentos deste artigo tivemos ocasião de ver que a existência do sagrado depende de uma forma de representação do mundo que se refere a um modo de percepção da energia que é produzida pela vida em grupo em momentos de interação particulares. Mais do que um modo de dividir o mundo, essas representações dizem respeito ao próprio homem, que percebe em si mesmo algo que parece também gozar desse estatuto sagrado, 
que é, como já vimos, aquilo que se costuma chamar de consciência moral. A existência dessa consciência não é um fato imaginário, um delírio, mas é a percepção de algo real, é o modo de representar a dualidade constitutiva da natureza humana, que é a um só tempo individual e social.

Antes de formular todos os termos de seu dualismo e definir em que consiste esse ser individual e esse ser social, ele começa por apontar como é possível que o ser social, que é naturalmente exterior, penetre no indivíduo e passe a fazer parte constitutiva de sua natureza: ele está encarnado na maior parte de nossos estados mentais. É interessante também notar neste trecho trazido logo abaixo, que o ponto de partida da discussão sobre a natureza humana é a necessidade de tratar do indivíduo para que se possa compreender melhor a sociedade, o que é o reverso da moeda que víamos em outros textos, em que o indivíduo não era explicável sem a sociedade. Assim, podemos estender o argumento e afirmar que o dualismo da natureza humana é um postulado sem o qual não existe a sociologia, pois postulá-la é, ao mesmo tempo, postular a existência da sociedade. Afinal, esta não existiria sem os indivíduos, não existiria se não fosse encarnada em cada consciência particular, ainda que a totalidade de seu ser não coincida com a soma dessas manifestações particulares:

Mesmo que a sociologia se defina como a ciência das sociedades, na realidade, ela não pode tratar dos grupos humanos, que são o objeto imediato de sua pesquisa, sem finalmente alcançar o indivíduo, elemento último de que esses grupos são compostos. Porque a sociedade não pode se constituir a não ser que penetre as consciências individuais e que as constitua "à sua imagem e semelhança"; sem querer dogmatizar excessivamente, é possível afirmar com alguma segurança que muitos de nossos estados mentais, inclusive aqueles mais essenciais, possuem uma origem social. Aqui, é o todo que, em larga medida, constitui a parte; por conseguinte, é impossível tentar explicar o todo sem explicar as partes, ao menos em contrapartida. (Durkheim, 1914, p. 206, tradução minha).

Portanto, compreender a sociedade e tudo aquilo que se relaciona à vida coletiva - os ideais, os ritos, o próprio sagrado - pressupõe que se conheça a natureza humana, que precisa ser dual. Caso contrário, não seria possível que a própria sociedade se constituísse, dado que não possuiria qualquer substrato real. Mas isso que aparece primeiramente como um postulado, Durkheim diz ser um fato verificável, mais do que isso, um fato amplamente percebido pelos próprios homens, e representado nos sistemas religiosos e mesmo filosóficos, 
de modo que essa sensação deve mesmo corresponder a algo real, senão nada mais explicaria sua universalidade e sua persistência no tempo.

O próprio homem de todos os tempos sempre teve o vivo sentimento dessa dualidade. Por toda parte ele se concebeu como sendo formado por dois seres radicalmente heterogêneos: o corpo, de um lado, a alma, de outro. [...] O corpo é parte constitutiva do universo material, tal como o conhecemos mediante nossa experiência sensível; a pátria da alma está em outro lugar e é para lá que ela tende a voltar incessantemente. Essa pátria é o mundo das coisas sagradas. Ela também é investida de uma dignidade que sempre se recusou ao corpo; assim, enquanto este é considerado essencialmente profano, aquela inspira alguma coisa desses sentimentos que sempre foram reservados àquilo que é divino. Ela é feita da mesma substância que os seres sagrados. (Durkheim, 1914, p. 210, tradução minha).

Seu dualismo não é, portanto, uma negação das teorias do homo duplex já estabelecidas, mas uma tentativa de explicar qual é a realidade que funda essa ideia, do mesmo modo que tentou mostrar aquilo que havia de verdadeiro nas religiões e em suas concepções sobre as divindades. Não é muito difícil intuir que a solução para essa questão consiste em afirmar que o corpo corresponde ao nosso "ser individual", enquanto a alma é aquilo que constitui o nosso "ser social". Mas o que é realmente interessante é que essa dualidade se dá em termos de uma dualidade de nossa vida representativa, e é em seu processo de formação que devemos buscar a origem desse dualismo real, porque não se trata, evidentemente, da existência de duas "substâncias" distintas e opostas.

O ser individual e o ser social são dois sistemas de "estados de consciência" (cf. Durkheim, 1968, p. 602), que diferem em termos de suas origens e de suas propriedades, e é por isso mesmo que se contradizem e se negam mutuamente. Resumidamente, o que veremos é que a dualidade da natureza humana é uma expressão da própria dualidade que existe entre o sagrado e o profano, é apenas um caso particular dessa divisão entre as coisas que está presente em todas as religiões.

Desse modo, somos levados a retornar ao processo dinamogênico que está na base da formação do sentimento de sagrado, mas olhando-o agora do ponto de vista do indivíduo, o que também ajuda a esclarecer algumas lacunas ainda não preenchidas. Com isso estaremos em condições de ver aquilo que Durkheim acreditava que os ideais são capazes de provocar nos indivíduos, 
explicando sua autoridade tão particular. O que vimos anteriormente é que o próprio sentimento do sagrado é a resultante da percepção que temos dessa "operação psíquica" que é chamada de "fusão", a comunhão das consciências individuais em uma consciência comum. Esse é o fato mais fundamental, é ele que explica o sagrado que, por sua vez, explica a autoridade e a desejabilidade das regras morais. É um fato ao mesmo tempo fisiológico, psíquico e sociológico, que tem impacto sobre o corpo, sobre os sentimentos, sobre as ideias:

Quando esses ideais movem nossa vontade, nós nos sentimos conduzidos, dirigidos, arrebatados por energias singulares que, evidentemente, não vêm de nós, mas se impõem a nós, e em relação às quais temos sentimentos de respeito, de reverência, mas as quais também reconhecemos como causa do conforto que recebemos; porque elas não podem se chegar até nós sem aumentar nosso tônus vital. E essas virtudes sui generis não se devem a nenhum tipo de ação misteriosa, são simplesmente os efeitos dessa operação psíquica, cientificamente analisável, mas singularmente criativa e fecunda, a que chamamos de fusão, de comunhão de uma pluralidade de consciências individuais em uma consciência comum. (Durkheim, 1914, p. 215, tradução minha).

Temos, assim, que a consciência dessa vida psíquica excepcional é o primeiro elemento a fornecer a percepção dessa natureza dual, na medida em que faz com que o indivíduo sinta nele forças que são diferentes daquelas que ele próprio possui. Mas isso não é suficiente. Essas forças não chegam até ele apenas nos momentos de efervescência, elas estão nele de forma permanente, porque estão encarnadas em certas representações que constituem a sua vida psíquica, que são as próprias representações coletivas, que dizem respeito tanto à sua vida intelectual quanto moral. É desse modo que os ideais passam a ser constitutivos das representações internas que orientam o pensamento e a volição dos indivíduos.

Aliás, ainda nesse mesmo artigo, ele descreve um processo muito semelhante àquele apresentado no texto sobre os juízos (Durkheim, 1911), em que vemos de que modo os ideais sociais são assimilados pelos indivíduos. Esse mecanismo é aqui apresentado como aquele mediante o qual o ser social penetra no ser individual, fazendo sua morada na pluralidade dos indivíduos que passam a representar esse ideal, cada qual à sua maneira. Uma vez enraizado, ele deixa de ser uma representação viva e pulsante e se converte no que poderíamos chamar de um "ideal mnêmico", isto é, fixado na memória, mas como 
toda lembrança, parcialmente destituído da potência da qual era investido no momento de sua gênese. Mas, veja-se bem, apenas parcialmente.

Esse ideal, que é também um tipo de representação, é sentido pelo indivíduo como sendo diferente de suas demais representações individuais, e, ao mesmo tempo, o tipo de reação psíquica que ele provoca não é do mesmo gênero que aquelas diretamente vinculadas à sua vida individual, porque nela existe algo que parece ser de outra natureza, que o vincula a um mundo estranho, que não coincide com aquele de sua própria existência, de seus próprios sentimentos. Essas forças são despertas e reavivadas especialmente nas celebrações coletivas, que fazem com que o indivíduo volte a ter contato direto com a verdadeira origem desse sentimento que ele experiencia em relação a essas representações muito especiais, inclusive aquelas gestadas em momentos de efervescência dos quais ele não chegou a tomar parte.

O que é importante ter em consideração aqui é que os ideais são um "produto da vida em grupo", e é nesse sentido que são sociais, pois as grandes concepções são tiradas do próprio seio da sociedade nos momentos de efervescência. Passado esse momento excepcional, a força do ideal não se dissolve plenamente, justamente porque a vida coletiva não deixa de existir, embora se mantenha em intensidade menor. A seguir, vemos como esses ideais coletivos são assimilados pela consciência individual, misturando-se com nossas próprias representações, engendrando um processo que não apenas garante a sua perpetuação, mas que também cria a percepção da dualidade de nosso ser:

Mesmo sendo nossas, essas representações falam a nós com outro tom, com uma inflexão diferente que o restante de nossos estados de consciência: elas nos ordenam, impõem-nos respeito, não nos sentimos em pé de igualdade em relação a ela. Assim percebemos que elas representam em nós algo que nos é superior. (Durkheim, 1914, p. 214, tradução minha).

Podemos ver nesse trecho um resumo de sua explicação sobre a dualidade da natureza humana. Ela é real, e exprime essa coexistência entre o nosso ser individual, que concerne a nosso organismo biológico, a nossa relação com o mundo, a nossas experiências pessoais, e o ser coletivo, que vive parcialmente em nós, mas tem outra origem. E não podemos existir sem que sejamos, a um só tempo, esses dois seres que são, na realidade, dois "estados de consciência”. A existência desse ser social como parte constitutiva da natureza 
humana é o que garante que o indivíduo esteja sempre vinculado à coletividade e a seus ideais, porque ele não pode negá-los sem ao mesmo tempo negar parte de si mesmo. É por isso que tomar a consciência da origem social de nossos valores não é suficiente para cessar a influência que eles exercem sobre nós, fazendo com que o cumprimento da regra moral apareça como algo tão fundamental, cuja violação, por mais que saibamos que não é um decreto divino, sempre provoca a sensação de violação da própria consciência, afinal o ideal que a anima é parte de nossa própria consciência.

Mas dizer dessas representações que elas são de origem exógena ainda não é suficiente para esgotar a questão a respeito de sua heterogeneidade e mesmo oposição em relação às representações individuais. Elas diferem destas porque possuem um caráter impessoal.

Assim, as representações individuais são pessoais, dizem respeito ao mundo tal como é percebido pela nossa sensibilidade, e seus imperativos práticos dizem sempre respeito aos nossos interesses pessoais, enquanto as representações coletivas orientam nossa conduta na direção de fins sociais, e intermedeiam nossa relação com o mundo a partir de conceitos partilhados intersubjetivamente. Aliás, é o próprio fato de que compartilhamos esses ideais o que garante a possibilidade da vida em comum, porque é isso que permite a comunicação, não apenas pela linguagem, mas também porque existe uma forma partilhada de pensar e de sentir, que não é idêntica, evidentemente, mas que possui elementos comuns:

Não é, portanto, sem razão que o homem sente-se duplo: ele realmente o é. Ele realmente possui dois estados de consciência que contrastam entre si em virtude de sua origem, sua natureza, dos fins para os quais eles tendem. Umas exprimem nosso organismo e os objetos com os quais ele se relaciona diretamente. Estritamente individuais, eles nos vinculam somente a nós mesmos, e não podemos nos desapegar deles assim como não podemos nos desapegar de nosso corpo. Os outros, ao contrário, advêm da sociedade; eles a traduzem em nós e nos vinculam a algo que nos ultrapassa. Sendo coletivos, são impessoais; eles fazem com que nos voltemos para os fins que temos em comum com os outros homens; é por eles, e somente por eles, que podemos nos comunicar com os outros. (Durkheim, 1914, p. 119, tradução minha).

A partir disso tudo, o que podemos afirmar é que a natureza humana é realmente dual, o que faz com que sejamos perpetuamente e naturalmente 
divididos contra nós mesmos. É isso também o que explica que a moral apareça a nós como um dever e como um bem, porque ela é um imperativo, porque não brota da nossa espontaneidade individual, mas ao mesmo tempo demanda a realização de um fim que consideramos bom, e cuja correta consecução nos provoca uma sensação de prazer sublime, porque somos alimentados pela energia da vida coletiva. Essa dualidade que resulta da coexistência dos dois tipos de estados mentais e, portanto, também de representações, é o que dá a sensação de que dentro de nós existe uma razão que é tanto teórica quanto prática.

Mas isso também é um fator de perpétua inquietude, pois esse "ser dilacerado" que faz com que o sagrado e o profano coexistam em seu ser é o que faz com que o homem jamais experimente qualquer forma de alegria pura, porque a ela "sempre se mistura alguma dor, porque não saberíamos satisfazer simultaneamente esses dois seres que vivem em nós" (Durkheim, 2012b, p. 36). Finalmente, é do fato de que as representações coletivas são constitutivas da nossa própria natureza que é possível que exista a sociedade não apenas enquanto um agregado físico de corpos, mas como um conjunto de consciências que conseguem interagir, na medida em que compartilham certas representações.

\section{Pressupostos e implicacōoes do sagrado como justificativa moral}

Se aceitarmos essa afirmação de Durkheim a respeito da dualidade da natureza humana, e se aceitarmos a sua explicação sobre sua ideia de sagrado como sendo uma representação coletiva a partir da percepção de algo real, resta-nos ainda fazer uma pergunta, talvez a mais crucial dentre todas as que já foram feitas aqui: por que a sociedade pode ser considerada um fim propriamente moral? Primeiramente, já vimos, porque ela é também uma consciência, e não uma entidade puramente material. Em segundo lugar, porque ela é a condição de existência do próprio homem. Em terceiro lugar, porque a autoridade da moral que ela prescreve corresponde a algo real, e é a única possível. Finalmente, porque não existe moral senão aquela criada socialmente, pois uma regra que não seja produto da coletividade não se impõe às consciências. Vamos agora elaborar um pouco mais essas afirmações.

O homem é um ser social não apenas porque as representações sociais estão presentes nele como parte constitutiva de sua personalidade, de sua vida 
prática e intelectual. Não apenas porque se ele não fosse moldado pela educação ele não seria esse ser tal como conhecemos, que difere dos animais porque é fruto da civilização. Ele é um ser social também porque é naturalmente gregário, porque há algo em sua constituição que faz com que ele precise e deseje esse contínuo influxo de energia que a vida coletiva lhe provê. Ele necessita de comida, de água, de sol, para que seu corpo seja nutrido e se mantenha saudável. Mas ele precisa da vida em grupo para alimentar seu ser "psíquico", porque a sobrevivência dessa parte de seu ser depende desse influxo dinamogênico que a vida coletiva produz.

Se o solipsismo fosse a verdadeira expressão de sua natureza, bastaria que as regras do direito, sancionadas pelo Estado, garantissem sua integridade física, seus bens materiais, seu direito de ir e vir. Seria suficiente um tipo qualquer de regulamentação que evitasse a guerra de todos contra todos, prevenindo que um lobo solitário atacasse outros lobos solitários. Assim também já vemos por que Durkheim opôs-se com tanta frequência à tese hobbesiana, e por que afirmou reiteradas vezes que os utilitaristas jamais conseguiram entender a moral, pois teriam falhado na compreensão daquilo que há de mais essencial na natureza humana: ela é dual, e se podemos conceder que existe uma parte dela que possui tendências egoístas, há também outra que é naturalmente altruísta, e é nesta, e não naquela, que reside sua dimensão propriamente moral.

A própria definição de consciência moral aponta para isso, na medida em que ela nada mais é do que a representação interna dessa potência externa; por isso ela está em nós - nossa consciência individual é sua base "física" - mas ela não é integralmente constituída por nós, pois é formada a partir dessa potência exterior. E justamente por se tratar de uma "potência" é que essa consciência moral fala a nós com tanta intensidade. Ela se impõe mesmo quando contraria nossas pulsões, nossos desejos individuais. Mas, paradoxalmente, o indivíduo experimenta um tipo especial de gratificação quando realiza essa ação, não tanto por causa do ato em si, ou do fim que esse ato promoveu, mas em virtude da reação de aprovação que recebe por parte da coletividade, por causa dessa atividade dinamogênica que chega até ele e alimenta essa outra parte de seu ser.

Agora podemos dar um passo um pouco arriscado, avançando em uma afirmação que provavelmente Durkheim não aceitaria prima facie, mas que pode ser autorizada por seu texto. Em vários momentos do percurso que 
estamos trilhando aqui, foi possível perceber que toda tentativa de explicar e fundar a moralidade sempre recai sobre a sociedade: ela é sua instância originária, e é também sua razão de ser, sua finalidade. Mas se podemos afirmar que a vida em grupo é suficiente para revelar processos que estão por trás de todo ideal e de toda regra moral, ela não parece ser satisfatória para explicar plenamente a questão sobre seu fundamento ou, para usar uma expressão menos forte, sobre sua efetiva desejabilidade.

Sim, podemos conceber que a moral seja produto da interação das consciências, que a existência da coletividade depende de que a moral continue a ser investida de autoridade, isto é, que continue falando aos corações e mentes e que, nessa medida mesma, continue regulando suas ações e mantendo a sociedade como corpo físico e espiritual. Isso ocorre porque os indivíduos se mantêm em um esquema de integração funcional e o ideal, que é sua alma, continua vivo nas consciências individuais. Mas por que isso é bom? Por que ao descobrir que Deus não existe, continuamos a desejar o ideal moral com a razão e com o sentimento? Por que continuamos a sentir e a reproduzir seu caráter sagrado? E mais, por que, do ponto de vista estritamente racional de uma ciência da moral, tudo isso pode ser justificado e afirmado como desejável?

A explicação que acabamos de ver, formulada a partir do postulado da dualidade da natureza humana, parece ser a resposta mais fundamental e mais evidente. Mas é também aqui que parece surgir um elemento quase paradoxal para uma teoria centrada sobre a sociedade. Ao fazer retroceder a questão da desejabilidade da moral e, por conseguinte, da própria sociedade, até um fato tão "básico" como a natureza gregária do homem, essa natureza mesma, ou melhor, o próprio homem, enquanto gênero humano e não como indivíduo singular, aparece, sorrateiramente, como justificativa mais fundamental da existência da moral, aquém da qual não é possível retroceder em busca algo mais essencial:

O produto por excelência da atividade coletiva é esse conjunto de bens intelectuais e morais a que chamamos de civilização [...]. Mas, por outro lado, é a civilização que fez do homem aquilo que ele é; é ela que o distingue do animal. O homem não é um homem senão porque ele é civilizado. Buscar as causas e as condições de que a civilização depende é, portanto, buscar as causas e as condições daquilo que há de mais especificamente humano no homem. (Durkheim, 1914, p. 226, tradução minha). 
A sociedade, legitimada diante dos indivíduos em virtude do caráter sagrado que estes atribuem a ela ou a qualquer uma de suas representações simbólicas, precisa ser esse fundamento, porque já não temos Deus, e nem temos uma razão prática em um sentido propriamente kantiano. Durkheim recorre à natureza humana, ao ser social do homem, porque fora da nossa vida coletiva, fora dos ideais morais que criamos, das explicações que temos sobre o mundo, das representações que temos sobre o bem, o belo, o verdadeiro, simplesmente não temos mais nada.

Recorrer à autoridade das representações coletivas para fundar a moral parece ser um último esforço para encontrar alguma ancoragem possível para aqueles valores que consciente ou inconscientemente prezamos, que respeitamos, que consideramos sagrados. Do fato de considerá-la a única ancoragem possível não resulta que a considere sólida, indestrutível, inequivocamente verdadeira, muito pelo contrário. Talvez a percepção de sua instabilidade, de sua fragilidade seja a própria condição de que a opinião pública continue a desempenhar esse papel, mesmo correndo o risco de fazer sua aura de sacralidade desaparecer no próprio ato de revelá-la.

\section{0 ideal moral de Durkheim: 0 indivíduo como o novo sagrado}

Agora podemos retornar para uma questão mencionada na introdução, qual seja, a defesa de um ideal moral particular, a que Durkheim chamou de "individualismo". O que importa perguntar é se esse ideal também pode gozar de um estatuto sagrado tal qual os ideais forjados no seio das concepções religiosas do mundo, e, além disso, trata-se ainda de saber como é possível que o indivíduo possa ser objeto de um respeito do mesmo tipo que o respeito religioso, mesmo depois de se revelar que é a força produzida pela interação social que funda o sentimento de sagrado. Ou seja, como é possível que a "descoberta" da sociedade como origem do sagrado possa justificar um culto ao indivíduo.

Vamos começar por esta última questão, tendo como ponto de partida a continuidade de um argumento apresentado anteriormente, quando vimos que a alma, considerada a parte mais "nobre" do ser humano, é, na realidade, a parte de seu ser que corresponde aos estados mentais que têm origem social. Voltando a Les formes élémentaires, vemos que a mesma explicação que vale 
para a ideia de alma vale também para a ideia de personalidade, que é fundada sobre essa dualidade real da natureza humana.

Já vimos que o fator impessoal é o "princípio espiritual" que serve como alma para a própria coletividade, é também o que constitui a substância das almas individuais, e é esse princípio, patrimônio coletivo, que promove a comunicação das consciências particulares. Mas, de outra parte, existe o fator propriamente pessoal, que diz respeito ao ser individual: é ele que fragmenta e diferencia esse princípio espiritual coletivo. É o corpo que opera essa individuação, que promove uma refração das representações coletivas, de modo que cada ser individual exprime esse princípio espiritual de uma forma recortada e particular. Com isso podemos ver a importância que continua a ter esse elemento impessoal para a formação da própria noção de personalidade, na medida em que esta é a expressão particular, única, de um princípio impessoal e coletivo (cf. Durkheim, 1968, p. 386).

Ora, para Durkheim, são esses princípios impessoais que nos tornam "pessoas", de modo que o culto ao indivíduo é, antes de tudo, uma afirmação daquilo que temos em comum com os outros homens, a nossa alma, as nossas formas particulares de exprimir esse ideal comum. Assim, o respeito ao indivíduo é um respeito a cada ser singular, mas é, também, a um só tempo, uma forma de deferência àquilo que é coletivo. Aliás, o próprio fato da individuação está enraizado na dinâmica social, e só se tornou possível pela própria representação coletiva do homem como ser que possui uma alma. Isso aponta de que modo um culto ao indivíduo não precisa se contradizer com a ideia de que é a vida coletiva que funda o sagrado. Vamos ver agora outras complicações que parecem estar implicadas nessa ideia.

A dimensão prescritiva na obra durkheimiana está diretamente vinculada ao ideal do individualismo moral, que orienta a sua defesa de uma educação moral laica, inteiramente racional. Ao tratar dos mecanismos de formação do sentimento de sagrado, voltamo-nos para uma das formas mais elementares e menos racionalizadas de ordenamento moral, as religiões totêmicas, porque nelas, segundo Durkheim, seria possível encontrar de forma explícita algo que está presente em todo tipo de sistema religioso e também de todo sistema moral.

Como podemos unir esses dois termos? Como podemos aproximar essa discussão sobre os arrebatamentos provocados pelos rituais tribais com a ideia de uma moral laica, essencialmente racional, que tem como deus o indivíduo, 
como crença a autonomia da vontade e como rito fundamental o livre exame (Durkheim, 1898)? Há sentido nesta última afirmação, ou ela é mera retórica? É possível que um ideal seja racional e sagrado ao mesmo tempo? Ou ainda, que um rito seja um livre exame?

A primeira coisa a se notar, conforme podemos ver no trecho mais abaixo, é que o individualismo ainda não se tornara o ideal de fato, o indivíduo ainda não se tornara um deus, e portanto ainda não seria possível afirmar mediante quais ritos se afirmaria, se a autonomia viria mesmo a se constituir como um dogma, e assim por diante, embora tudo indique que ele acreditava que seria possível que se formassem ritos que não fossem investidos de um caráter propriamente religioso, e a existência de determinados ritos ou celebrações civis seriam a evidência disso:

Qual é a diferença essencial entre uma assembleia de cristãos celebrando as principais datas da vida de Cristo, ou de judeus festejando seja a saída do Egito, seja a promulgação do Decálogo, e uma reunião de cidadãos que comemoram a instituição de uma nova constituição ou qualquer outro grande acontecimento da vida nacional? [...] Não podemos mais nos apaixonar pelos princípios em nome dos quais o cristianismo recomendava aos senhores que tratassem humanamente seus escravos e, por outro, a própria ideia que antes se fazia da igualdade e da fraternidade humana nos parecem ainda deixar espaço a injustas desigualdades. Sua piedade para com os humildes nos parece demasiado platônica; desejamos uma que fosse mais eficaz; mas ainda não vemos claramente aquilo que ela deve ser ou como ela deve se realizar nos fatos. Resumindo, os antigos deuses envelheceram ou morreram, e novos deuses ainda não nasceram. (Durkheim, 1968, p. 610-611, tradução minha).

Assim, o que vemos é a afirmação da necessidade e da esperança de novos ideais, substituindo aqueles então remanescentes, cujo brilho e calor não são mais do que fogos-fátuos, incapazes de despertar a adesão intensa aos ideais de outrora. Mesmo a "fé revolucionária" já não fala aos corações, porque foi marcada por muitas decepções. Mas quanto a saber em que consistirá a nova fé e sob quais símbolos ela poderá se expressar, trata-se de "uma questão que ultrapassa as faculdades humanas"(Durkheim, 1968, p. 612, tradução minha). Por que, então, mesmo diante dessa incerteza em relação ao futuro, ele defendeu o individualismo como ideal moral da modernidade? Talvez a discussão que acabamos de fazer sobre o sagrado nos ajude a encontrar uma 
resposta, conquanto é possível afirmar que, segundo Durkheim, este é o único ideal que pode ser realmente coletivo, que pode ser partilhado pela pluralidade das consciências sem se chocar com os demais "sagrados particulares" dos grupos menores, desde que os sagrados particulares não sejam contrários a esse sagrado geral.

O respeito humano era, para ele, a única crença suficientemente ampla e formal para garantir a manutenção de representações compartilhadas que, como vimos, é condição para a continuidade da existência do ser social - seja encarnado parcialmente nas consciências particulares, seja enquanto grupo mesmo, com seu corpo e sua alma. Porque é preciso que o sagrado persista, na medida mesma em que isso é parte da própria condição humana. Eliminálo seria eliminar a dualidade da natureza humana, seria enfraquecer ou fazer desaparecer sua alma e, por conseguinte, desnaturar sua natureza.

$\mathrm{O}$ homem até poderia continuar a viver em coletividade, mas perderia essa parte mais nobre de sua existência, e sua ação passaria ser apenas aquela autointeressada, fazendo evanescer aquilo a que se chama de ação propriamente moral, simplesmente porque sua consciência moral passaria por um lento processo de decomposição, de enfraquecimento, como sintoma do perecimento do próprio ideal moral, que desaparece no momento em que o sentimento de sagrado deixa de existir. Assim vemos como o sentimento de sagrado explica e justifica a defesa do individualismo, na medida em que este já é - ao menos em alguma medida - e deve continuar sendo a crença que goza de um estatuto sagrado por excelência, pois é a única que o pode ser, é a única logicamente aceitável pela pluralidade de consciências tão díspares, tão individualizadas.

Talvez a aposta de Durkheim na permanência e no desenvolvimento do individualismo moral fosse menos um prognóstico baseado na certeza de sua inevitabilidade e mais uma "profissão de fé", ou, para fazer justiça ao seu laicismo, uma esperança. É verdade que Durkheim nos leva a crer nessa inevitabilidade em virtude de sua afirmação de que o sagrado é permanente e universal. Segundo William Pickering (1990, p. 92, tradução minha), essa afirmação a respeito da persistência do sagrado teria sido o seu grande erro:

Afirmar que todas as sociedades são igualmente religiosas ou que possuem o mesmo montante de religião, mas sob diferentes formas, é algo falacioso, senão ridículo. $\mathrm{E}$ o mesmo pode ser dito a respeito do sagrado. A menos que lide de forma leviana com os termos religião e sagrado, é absurdo sugerir que as

Horizontes Antropológicos, Porto Alegre, ano 19, n. 40, p. 395-421, jul./dez. 2013 
modernas sociedades ocidentais façam o mesmo uso de conceitos religiosos e rituais, ou do sagrado, que as sociedades primitivas, ou que as sociedades cristãs da Idade Média ou os países europeus durante a Idade Média.

Esse importante artigo de Pickering possui muitos e inquestionáveis méritos, como a apresentação rigorosa das definições de religião e de sagrado e de sua utilização da teoria durkheimiana para pensar o mundo contemporâneo, e vice-versa, mostrando que uma observação mais superficial das sociedades modernas representaria uma contestação factual do postulado de Durkheim sobre a persistência do sagrado, e, acrescento, em relação a seu prognóstico quanto ao futuro do individualismo. Todavia, a leitura muito literal realizada por Pickering parece desviar a atenção daquilo que há de mais importante nessa discussão durkheimiana sobre o sagrado, que é uma interpretação moral do mundo, na qual o sagrado deveria persistir, por todas as razões expostas acima. Quanto à afirmação de que Durkheim teria dito que todas as sociedades possuem o mesmo montante e a mesma relação com o sagrado, também é possível tecer diversas objeções, a começar pelo duplo sentido que possui o conceito de religião e de religiosidade.

É verdade que ele considerava que o pensamento religioso ainda não havia encontrado o termo de sua trajetória, porque "é contrário a todas as evidências que as causas que suscitaram as religiões no passado tenham cessado de uma vez por todas" (Durkheim, 1907, p. 51, tradução minha). Mas isso não significa que ele tenha dito que todas as sociedades teriam sempre o mesmo "montante" de religião, que seriam igualmente religiosas, ou que o próprio sagrado continuaria a desempenhar o mesmo papel. A própria ideia do individualismo como "mínimo sagrado comum" já é suficiente para afirmar o contrário disso, assim como seu diagnóstico sobre o grau de importância menor de se ter uma crença comum nas sociedades modernas, donde a necessidade de que a solidariedade seja garantida também pela divisão do trabalho.

No mesmo texto que acabei de citar, vemos expresso de outro modo seu diagnóstico sobre o necessário perecimento das religiões tradicionais, sua incerteza sobre o futuro concreto das novas formas religiosas, sua aposta na continuidade do pensamento religioso e sua esperança de que esse fosse cada vez mais perpassado pela racionalidade, a tal ponto de não guardar 
mais resquícios da forma e do conteúdo irracionais e obscuros das religiões precedentes:

Quanto a saber quais serão as formas religiosas do futuro, trata-se de uma profecia que o estado de nossas consciências não permite fazer. Tudo aquilo que podemos presumir é que elas serão ainda mais penetradas de racionalidade do que as mais racionais religiões atuais, e que o sentimento social, que sempre foi a alma das religiões, se afirmará mais diretamente e mais expressamente do que no passado, sem se revestir de mitos e de símbolos. (Durkheim, 1907, p. 51, tradução minha).

\section{Consideracõos finais}

Que as coisas não tenham seguido esse caminho descrito por Durkheim, é algo difícil de duvidar. Não porque o "individualismo" não pudesse ser esse novo sagrado, mas simplesmente porque esse foi um projeto que não vingou em sua plenitude. E talvez a contrapartida disso seja um fenômeno ambíguo e paradoxal: se de um lado um sagrado comum parece de fato não ter se consolidado, ao menos não no sentido previsto e idealizado por Durkheim, de outro, sua hipótese sobre a progressiva racionalização das religiões é igualmente inverossímil, assim como o próprio diagnóstico de Pickering. Pois, se temos parcelas de diferentes sociedades suficientemente laicizadas, ou que comungam em torno de "sagrados mundanos", tais como versões reelaboradas do individualismo, também vemos bem diante dos nossos olhos a persistência das grandes religiões tradicionais, algumas delas metamorfoseadas em versões ainda mais dogmáticas do que as que existiam no começo do século XX.

Da mesma forma, também assistimos ao surgimento de novas profissões de fé que não parecem representar ganho algum em termos de racionalidade, de percepção de seu caráter social, ou de libertação de formas míticas e simbólicas. Se for para apontar qual foi o erro de Durkheim, certamente não foi a tese sobre a persistência do sagrado ou da religião, mas o prognóstico - ou talvez a crença - de que o novo sagrado congregaria corações e mentes em torno de um ideal comum, ou ainda, que as novas formas de religiosidade que viessem a surgir seriam mais penetradas de racionalidade do que as mais racionais religiões de então. 


\section{Referências}

DURKHEIM, É. Review: De l'irreligion de l'avenir. Revue Philosophique, n. 23, p. 299-311, 1887.

DURKHEIM, É. Les principes de 1789 et la sociologie. Revue Internationale de l'enseignement, v. 9, p. 450-456, 1890.

DURKHEIM, É. L'individualisme et les intellectuels. Revue Bleue, t. 10, p. 7-13, 1898.

DURKHEIM, É. Review: Ross, Edward Alsworth, The Genesis of Ethical Elements. Année Sociologique, n. 4, p. 308-309, 1901.

DURKHEIM, É. La Question Religieuse: enquête internationale. Mercure de France, v. 61, p. 51, 1907.

DURKHEIM, É. Idéal moral, conscience collective et forces religieuses. Anotações de Georges Davy. 1909.

DURKHEIM, É. Jugements de valeur et jugement de réalité. In: ATTI DEL IV Congresso Internazionale di Filosofia. Bologna, 1911. v. 1, p. 99-114.

DURKHEIM, É. Le dualisme de la nature humaine et ses conditions sociales. Scientia, v. 15, p. 206-221, 1914.

DURKHEIM, É. Les formes élémentaires de la vie religieuse. Paris: Presses Universitaires de France, 1968.

DURKHEIM, É. O ensino da moral na escola primária. Novos Estudos Cebrap, v. 78, p. 61-75, 2007.

DURKHEIM, É. A educação moral. Petrópolis: Vozes, 2008.

DURKHEIM, É. Considerações a respeito dos cultos primitivos e a função do sagrado. Debates do NER, v. 1, n. 22, p. 63-66, 21 dez. 2012a.

DURKHEIM, É. O problema religioso e a dualidade da natureza humana. Debates do NER, v. 1, n. 22, p. 27-62, 21 dez. 2012b. 
PAOLETTI, G. Durkheim's 'Dualism of Human Nature': Personal identity and social links. Durkheimian Studies, v. 18, n. 1, p. 61-80, 2012.

PICKERING, W. S. F. The eternality of the sacred: Durkheim's error? Archives de sciences sociales des religions, v. 35, n. 69, p. 91-108, janv./mars 1990.

WEISS, R. Émile Durkheim e a fundamentação social da moralidade. Tese (Doutorado em Filosofia)-Faculdade de Filosofia, Letras e Ciências Humanas, Universidade de São Paulo, São Paulo, 2011.

WEISS, R. From ideas to ideals: effervescence as the key to understanding morality. Durkheim Studies, v. 18, n. 1, p. 81-98, 2012a.

WEISS, R. O sagrado, a dualidade humana e a natureza social da religião: apresentação às traduções. Debates do NER, v. 1, n. 22, p. 17-26, 21 dez. $2012 b$. 